\title{
Kulikowski, Michael, Die Goten vor Rom
}

\section{Stéphane Gioanni}

\section{OpenEdition \\ Journals}

Édition électronique

URL : http://journals.openedition.org/ifha/2164

DOI : 10.4000/ifha. 2164

ISSN : 2198-8943

Éditeur

IFRA - Institut franco-allemand (sciences historiques et sociales)

\section{Référence électronique}

Stéphane Gioanni, « Kulikowski, Michael, Die Goten vor Rom », Revue de l'IFHA [En ligne], Date de recension, mis en ligne le 01 janvier 2010, consulté le 22 septembre 2020. URL : http:// journals.openedition.org/ifha/2164 ; DOI : https://doi.org/10.4000/ifha.2164

Ce document a été généré automatiquement le 22 septembre 2020.

(CIFHA 


\title{
Kulikowski, Michael, Die Goten vor Rom
}

\author{
Stéphane Gioanni
}

Cette publication constitue la traduction allemande (par Bettina von Stockfleth) du deuxième livre de l'historien américain M.K., paru en 2007 sous le titre Rome's Gothic Wars : From the Third Century to Alaric dans la nouvelle collection « Key Conflicts of Classical Antiquity » (Cambridge University Press). Après avoir consacré une première monographie aux cités de l'Espagne tardo-antique (Late Roman Spain and Its Cities, 2004), M.K., spécialiste de l'histoire de la Méditerranée occidentale, s’intéresse ici aux relations entre l'Empire romain et les Goths, l'un des plus importants groupes barbares de l'Antiquité. Le prologue place le lecteur devant les portes de Rome («Vor den Toren Roms »), en août 410, au moment où Alaric s'apprête à mettre à sac l'ancienne capitale délaissée par l'empereur installé à Ravenne. Le récit de cet événement traumatisant, qui poussa Augustin à écrire la Cité de Dieu pour démontrer que la christianisation de l'Empire n'était pas responsable de ce drame, permet de capter l'attention des lecteurs avant d'étudier les origines historiques et idéologiques des Goths. L'ouvrage est composé de huit chapitres classés chronologiquement qui retracent l'histoire des Goths et de leurs relations avec l'Empire depuis le milieu du IIIe siècle.

Prenant ses distances avec les représentations romantiques des «barbares » qui ont fleuri depuis le XIXe siècle, l'auteur cherche à comprendre qui étaient précisément les Goths, sans se limiter au point de vue des spécialistes du monde romain (chap. 1 : «Die Goten vor Konstantin "; chap. 2 : «Das römische Imperium und die barbarische Gesellschaft "; chap. 3 : " Die Suche nach dem Ursprung der Goten »). Refusant de considérer les Goths comme un seul peuple originaire de Scandinavie, l'auteur développe la thèse que les Goths sont nés, comme les Francs et les Alamans, dans la résistance à l'occupation et au pouvoir romains. Depuis le milieu du IIIe siècle, la puissance des Goths aux frontières de l'Empire serait donc la conséquence directe de la présence romaine sur le limes, de l'oppression sur les populations locales mais aussi de l'extension de citoyenneté romaine qui attisa les ambitions politiques et les phénomènes de compétition dans l'ensemble de l'Empire (chap. 4 : « Römische Politik und der Aufstieg der gotischen Macht »; chap. 5 : «Goten und Römer 332-376»). Avant 
même d'être perçus comme un peuple uniforme par les autorités, les Goths ne seraient donc que la somme de petits groupes d'origines diverses qui se seraient réunis pour faire face à l'armée impériale à laquelle ils infligèrent quelques-unes des pires défaites de son histoire comme celle d'Adrianopolis, en 378, où les troupes romaines furent anéanties et où l'empereur fut tué (chap. 6 : «Die Schlacht von Adrianopel »; chap. $7:$ « Theodosius und die Goten »). Le dernier chapitre (chap. 8 : "Alarich und die Plünderung Roms ») s'intéresse plus précisément à l'avancée d'Alaric qui allait pénétrer dans Rome en 410. Selon M.K., le sac de Rome est à l'origine de la défaite d'Alaric dans la mesure où cette conquête traduit la volonté de prendre possession de l'ancienne capitale et de s'inscrire dans l'histoire romaine. Cet objectif ne fut véritablement atteint qu'après la chute de l'empire d'Occident et l'instauration de la royauté gothique en Italie dont l'âge d'or se situe sous le règne de Théodoric qui aspirait à la restauration des symboles de la romanité (« Epilog : Die Zeit nach Alarich »).

L'ouvrage se termine, comme dans l'édition anglaise, par la liste des abréviations, par des notes complémentaires contenant surtout les références des auteurs anciens (Lactance, Zosime, Ammien-Marcellin, Tacite, Eusèbe, Aurélius Victor et surtout l'Histoire des Goths de Jordanès) et par une présentation analytique de lectures complémentaires sur les Goths dans l'historiographie contemporaine.

Stéphane Gioanni (École française de Rome) 